\title{
Sistema de Informação para a Ação: Subsídios para a Atuação Prática dos Programas de Saúde dos Trabalhadores a Nível Local ${ }^{1}$
}

\author{
Action-Oriented Information Systems: Subsidies for Activities by \\ Workers' Health Programs at the Local Level
}

\author{
Victor Wünsch Filho'; Maria M. Settimi² \\ Clara S. W. Ferreira ${ }^{2}$; José Carlos do Carmo²; \\ Ubiratan P. Santos ${ }^{2}$; Norton A. Martarello ${ }^{2}$; Danilo F. Costa ${ }^{2}$
}

WÜNSCH-FILHO, V.; SETTIMI, M. M.; FERREIRA, C. S. W.; CARMO, D. C.; SANTOS, U. P.; MARTARELLO, N. A. \& COSTA, D. F. Action-Oriented Information Systems: Subsidies for Activities by Workers' Health Programs at the Local Level. Cad. Saúde Públ., Rio de Janeiro, 9 (2): 136-148, Apr/Jun, 1993.

Over the course of recent decades, Brazil has become an industrialized society. From an epidemiological perspective and considering changes that have been occurring in the Brazilian population, particularly concerning demographic and epidemiological transitions, this paper discusses the need to adapt the epidemiological surveillance system in order to incorporate the surveillance of non-transmissible diseases. The authors analyze the information system for workrelated accidents in the Workers' Health Program, under SUDS (the Unified Decentralized Health System) for the Mandaqui Region (in the Northern part of the city of São Paulo), based on data from a local metalworking industry identified by the information system as a high-risk site for work-related accidents. The article also focuses on the importance of organized workers participating in actions to control work-related accidents. Although such participation is not always possible, the health sector must incorporate the workers' own concrete experience in order to develop more effective actions to prevent accidents at the workplace.

Key words: Occupational Health Program; Epidemiologic Surveillanc; Accidents Occupational

\section{INTRODUÇÃO}

O adensamento da população brasileira em grandes centros urbanos, decorrente do processo de industrialização implantado a partir dos anos 50 , tem gerado problemas de várias ordens, problemas estes inter-relacionados e com so-

\footnotetext{
I Este trabalho faz parte do projeto "Sistema de Vigilância Epidemiológica para Acidentes e Doenças do Trabalho na Região do SUDS-R-6", financiado pelo convênio Programa Metropolitano de Saúde/Banco Mundial, integrante do Núcleo de Investigação e Avaliação das Propostas do SUDS-SP, do Instituto de Saúde.

${ }^{2}$ Programa de Saúde dos Trabalhadores, SUDS-R-6. Rua Voluntários da Pátria, 4301, Mandaqui. São Paulo, SP, 02401-400, Brasil.
}

luções que envolvem aspectos amplos tais como a política agrária e a do uso social do solo urbano. As precárias condições de vida destas populações, vivendo nestes espaços urbanos industrializados e geralmente degradados, podem ser detectadas pelos indicadores de saúde nestas áreas.

No contexto destas mudanças do espaço geográfico brasileiro, os profissionais de saúde devem considerar dois fenômenos: o da "transição demográfica" e o da "transição epidemiológica", discutidos em trabalhos recentes (Kalanche et al., 1987; Landrigan, 1989; Ramos et al., 1987; Saad \& Camargo, 1989; Troyano, 1988). Denomina-se transição demográfica o envelhecimento gradual da população brasileira. O fenômeno da transição epidemiológica é 
caracterizado pelo fato das doenças não-transmissíveis estarem assumindo no país o mesmo nível de importância das doenças infecto-contagiosas. Tais fenômenos de transição acarretam sérias dificuldades para o planejamento de saúde no país, que necessita operar simultaneamente com patologias típicas de países periféricos e aquelas prevalentes nas sociedades capitalistas centrais.

$\mathrm{O}$ atual sistema de vigilância epidemiológica no Brasil, estruturado fundamentalmente para atender às demandas das doenças transmissíveis, não tem se mostrado ágil o suficiente para acompanhar as transições ocorridas na população. Parte da necessária transformação da vigilância em saúde está relacionada à regionalização e à efetiva municipalização do sistema de saúde, pois as equipes de saúde locais, detendo um conhecimento mais aprofundado dos problemas referentes à sua área de atuação, poderão planejar suas ações de forma mais adequada. Considerando-se as especificidades das questões relativas à saúde dos trabalhadores, o enfoque a ser dado pela equipe de saúde em determinada região da cidade de São Paulo, por exemplo, deverá ser qualitativamente diferente de outra equipe que, trabalhando em um município do interior do estado, com uma área rural mais expressiva, deverá gerar questões de saúde relativas ao trabalho ligadas, sobretudo, ao uso na produção agrícola de mão-de-obra volante e da utilização intensa de pesticidas.

É objetivo deste trabalho discutir e refletir sobre um sistema de informação para a ação referente aos acidentes decorrentes do trabalho no espaço urbano. A discussão terá como base o sistema implantado pelo Programa de Saúde dos Trabalhadores (PST) na área do SUDS-R-6 (Mandaqui), situado na zona norte do município de São Paulo.

\section{ASPECTOS DA MORTALIDADE NO MUNICÍPIO DE SÃO PAULO}

Os dados de mortalidade no município de São Paulo dos últimos anos mostram que a principal causa de morte na faixa etária dos 5 aos 40 anos de idade está registrada como devido a causas externas (Seade, 1987). Sob esta deno- minação estão os acidentes, sejam de trânsito, trabalho ou lazer, as mortes por violência, os homicídios e suicídios. É somente a partir da faixa etária dos 40 anos que as mortes devido a causas externas situam-se na segunda posição, logo após as decorrentes de doenças cardiovasculares. Até os 5 anos de idade, são as doenças infecciosas as que mais causam mortes.

Os dados mostram a grande quantidade de acidentes com veículos a motor. Os demais acidentes, os quais supõem-se involuntários, estão em outro grupo, sem especificar causa, mas seguramente o padrão da distribuição de acidentes no Brasil é diferente daquele dos países desenvolvidos, onde, após a identificação dos problemas e vários anos de programas de intervenção, houve redução acentuada dos acidentes de trânsito e de trabalho. Nestes países, aparecem, hoje, como mais importantes os acidentes no domicílio, os de lazer e os relacionados aos esportes (Rogmans, 1989).

Para a estimativa da População Economicamente Ativa (PEA), a Fundação Estadual de Análise de Dados (Seade) considera as crianças a partir dos 10 anos de idade. É na faixa etária dos 10 aos 40 anos onde se concentra a parcela da população brasileira que forma o maior contingente da força de trabalho utilizada pelo setor produtivo. Conseqüentemente, pode-se especular que grande parte das mortes devido a causas externas pode ter sido acarretada por acidentes relacionados ao trabalho. É provável que parte significativa das mortes de acidentes de trânsito na capital de São Paulo esteja ligada ao trabalho, atingindo o trabalhador durante o seu período de atividade, como motoristas, office-boys, etc., ou durante o seu trajeto entre a casa e o local de trabalho, ou vice-versa. Por outro lado, os trabalhadores do setor informal da economia (Chala, 1986; Dedecca \& Ferreira, 1988; Oliveira, 1988; Saad \& Camargo, 1989; Troyano, 1988), por não serem registrados, quando sofrem acidentes, não têm estes definidos como decorrentes do trabalho.

Os dados de mortalidade condensados pela Fundação Seade, embora sugiram a gravidade da situação, não permitem um dimensionamento adequado das especulações aqui levantadas.

A situação dos acidentes de trabalho no Brasil, hoje, tem raiz histórica no processo de 
"industrialização a qualquer custo", que gerou distorções estruturais onde foi privilegiada a produção, em detrimento dos aspectos sociais envolvidos no processo de trabalho (Anônimo, 1989). Durante a década de 80, muito se discutiu a respeito das questões relacionadas aos acidentes do trabalho no Brasil. Estudos apontaram para o fato inusitado das estatísticas mostrarem uma diminuição do número de acidentes do trabalho, enquanto, paradoxalmente, ocorria um maior número de óbitos relativos à PEA (Possas, 1981; 1987). Se a causa determinante da redução do número de acidentes fosse a melhoria das condições de trabalho, esperar-seia, a exemplo de outros países, a diminuição também do número de óbitos devido aos acidentes do trabalho. Como isso não ocorreu, infere-se que os acidentes continuam a ocorrer, mas passaram a ser mascarados através de artifícios legais ou de subnotificação (Costa et al., 1989; Possas, 1981; 1987). Mas, apesar do problema ter sido levantado e propostas virem sendo apresentadas por técnicos e sindicatos de trabalhadores, pouco se caminhou no sentido de intervenções efetivas na prevenção dos riscos envolvidos neste tipo de acidente.

Acredita-se que levantamentos sistemáticos de morbidade, através de um sistema de vigilância, podem fornecer os elementos necessários para qualificar as propostas de intervenção, estabelecendo um maior poder de ação para fazer com que as empresas introduzam mudanças no processo de produção ou na organização do trabalho.

\section{O SISTEMA DE VIGILÂNCIA EM ACIDENTES E DOENÇAS DO TRABALHO DO PROGRAMA DE SAÚDE DOS TRABALHADORES DO SUDS-R-6 (MANDAQUI)}

Uma proposta de sistema de vigilância para acidentes e doenças do trabalho foi implantada no final de 1988 e continua sendo desenvolvida na zona norte da cidade de São Paulo, na área delimitada pelo SUDS-R-6 (Sistema Unificado e Descentralizado de Saúde - Regional 6, uma das regiões estaduais de saúde da Região Metropolitana de São Paulo). Deste SUDS fazem parte os subdistritos de Santana, Tucuruvi, Vila
Guilherme e Vila Maria. Em 1988, esta região tinha uma população estimada em 1.043.231 habitantes, PEA de $44 \%$ e cerca de 2.400 indústrias (Costa et al., 1989). Os primeiros resultados divulgados referem-se aos meses de outubro, novembro e dezembro do mesmo ano (Santos et al., 1989; 1990). Os dados referentes aos anos de 1989 e 1990 já foram analisados e divulgados, através de boletins do Programa de Saúde dos trabalhadores (PST) do SUDS-R-6, junto aos sindicados da região. Desde 1991 que os dados vêm sendo trabalhados mensalmente, pois a periodicidade das informações é um dos fatores que devem caracterizar um sistema de vigilância em saúde.

A população do estudo é a população trabalhadora assistida nos hospitais da área credenciados para atender acidentados do trabalho. Muitos dos acidentes que ocorrem fora desta região são atendidos dentro dos limites do SUDS-R-6. Por outro lado, acidentes que ocorrem dentro da sua área de abrangência podem estar sendo atendidos em outros locais. As informações são extraídas das Comunicações de Acidentes do Trabalho (CATs), instrumento de registro de dados implantado a nível nacional pelo extinto Ministério da Previdência e Assistência Social.

Há consenso na equipe do PST do SUDS-R-6 que dois pontos são fundamentais entre as prioridades de ação dos programas de saúde dos trabalhadores: a) informações periódicas que possam estar direcionando dinamicamente as investigações dos acidentes e as intervenções para mudanças necessárias no ambiente e no processo de trabalho; e b) a participação ativa dos trabalhadores e seus sindicatos nesta atividade.

\section{ESTUDO DE CASO}

Com a implantação deste sistema na região do SUDS-R-6, as primeiras informações geradas delinearam duas principais estratégias para desencadear ações de investigação de acidentes e intervenção nos ambientes de trabalho: a primeira, concentrar a investigação naquelas empresas onde estivessem ocorrendo um maior número de acidentes; e a segunda, investigar os acidentes que fossem considerados graves. 
Discute-se aqui um caso onde empregou-se a primeira estratégia.

A análise dos acidentes do trabalho atendidos na região no último trimestre de 1988 mostrou um total de 2.339 ocorrências. Foram listadas as empresas e o respectivo número de acidentes. A investigação aqui descrita refere-se à empresa metalúrgica da região que apresentou o maior número de acidentes, independentemente da gravidade, no período estudado.

\section{O Ambiente Fabril}

A zona norte do município de São Paulo caracteriza-se por possuir um parque industrial metalúrgico formado basicamente por pequenas empresas. A empresa metalúrgica objeto deste estudo é uma indústria de médio porte que produz peças para carros de diversas marcas, tratores e implementos agrícolas, além de peças para tanques militares.
A planta industrial da empresa é caracterizada pela predominância de operações do setor de estamparia, tendo como setores complementares a forjaria, montagem com solda, jateamento de peças com areia, rebarbação, pintura, usinagem, ferramentaria e manutenção. Os agentes físicos e químicos presentes nos diferentes ambientes são apresentados na Tabela 1 . O ambiente de trabalho apresenta arranjo físico inadequado, com equipamentos, máquinas e bancadas muito próximas umas das outras e sem sinalização de áreas; livre acesso do corpo do trabalhador à zona de perigo nas prensas; e uso inadequado dos dispositivos de segurança das mesmas. $\mathrm{O}$ setor de estamparia funciona em um sistema de três turnos e os demais, em dois turnos. Trabalham na empresa, em média, 260 pessoas, sendo 12 na área administrativa, das quais 8 são homens e 4, mulheres. Os outros 248 trabalhadores operam na produção e são todos do sexo masculino. Destes, cerca de $40 \%$ trabalham no setor de estamparia.

TA Bela 1. Agentes Físicos e Químicos Presentes no Ambiente de Trabalho da Empresa Metalúrgica Estudada

\begin{tabular}{|c|c|c|c|c|c|c|c|c|}
\hline \multirow[t]{2}{*}{ Setores } & \multicolumn{4}{|c|}{ Agentes Físicos Presentes } & \multicolumn{4}{|c|}{ Agentes Químicos Presentes } \\
\hline & Ruído & Calor & Vibração & $\begin{array}{c}\text { Fumos } \\
\text { Metálicos }\end{array}$ & Solventes & $\begin{array}{l}\text { Tintas e } \\
\text { Vernizes }\end{array}$ & $\begin{array}{c}\text { Desengraxantes } \\
\text { Clorados } \\
\end{array}$ & Sílica \\
\hline 1. Estamparia & $\mathrm{X}$ & & $\mathrm{X}$ & & & & & \\
\hline 2. Forjaria & $\mathrm{X}$ & & & $\mathrm{X}$ & & & & \\
\hline 3. Ferramentaria & $\mathrm{X}$ & & & $\mathrm{X}$ & & & & \\
\hline 4. Manutenção & $\mathrm{X}$ & & & $\mathrm{X}$ & & & & \\
\hline 5. Solda & & $\mathrm{X}$ & & $\mathrm{X}$ & & & & \\
\hline 6. Pintura & & & & & $\mathrm{X}$ & $\mathrm{X}$ & $\mathrm{X}$ & \\
\hline \multicolumn{9}{|l|}{ 7. Almoxarifado } \\
\hline 8. Polimento & $\mathrm{X}$ & & $\mathrm{X}$ & & & & & \\
\hline 9. Rebarba & $\mathrm{X}$ & & & & & & & $\mathrm{X}$ \\
\hline $\begin{array}{l}\text { 10. Jateamento } \\
\text { de areia }\end{array}$ & & & & & & & & $\mathrm{X}$ \\
\hline
\end{tabular}

\section{O Enfoque do Serviço de Saúde através dos Dados Secundários}

Dos 16 acidentes desta empresa detectados pelo sistema de informações no último trimestre de 1988, constatou-se que apenas 10 dos acidentes registrados $(62,5 \%)$ ocorreram efetivamente no período estudado. $\mathrm{O}$ restante são eventos ocorridos em períodos anteriores do mesmo ano (ver Tabela 2). Este fato se explica pela origem dos dados deste sistema, estruturado nas contas hospitalares, apresentados à Unidade de Avaliação e controle (UAC) do SUDS-R-6. Por motivos variados, muitas vezes há retardo na apresentação da conta hospitalar, 
resultando em atraso no registro da informação. Este é um dos fatores limitantes de um sistema de coleta de informações com características passivas.

A distribuição dos acidentes segundo causa, diagnóstico, localização da lesão e função do trabalhador pode ser observada nas Tabelas 3, 4, 5, e 6 . Considerando-se o diagnóstico principal da CAT, quatro acidentes (25\%) foram considerados graves. Dentro dos critérios estabelecidos na codificação, são considerados acidentes graves: os politraumatismos, os traumatismos crânio-encefálicos, as amputações, as fraturas, as luxações, as asfixias, os afogamentos e as roturas de vísceras e de hérnias.

Frente a esta situação epidemiológica, evidenciando um processo de trabalho com alto grau de risco, optou-se pelo aprofundamento da análise dos acidentes detectados, de acordo com as seguintes etapas: levantamento das 16 CATs registradas para análise detalhada, reunião com trabalhadores acidentados e vistoria na empresa.

TABELA 2. Distribuição dos Acidentes de Trabalho na Empresa Metalúrgica Estudada, segundo o Período de Ocorrência

\begin{tabular}{lcc}
\hline \hline Período & $\mathrm{N}^{\mathrm{o}}$ & $\%$ \\
\hline 1 $^{\mathrm{o}}$ semestre de 1988 & 1 & 06,3 \\
Julho, agosto, setembro de 1988 & 5 & 31,3 \\
Outubro de 1988 & 6 & 37,5 \\
Novembro de 1988 & 2 & 12,5 \\
Dezembro de 1988 & 2 & 12,5 \\
\hline Total & 16 & 100,0 \\
\hline \hline
\end{tabular}

TABELA 3. Distribuição dos Acidentes Ocorridos na Empresa segundo Causa

\begin{tabular}{lcc}
\hline \hline Causa do Acidente & $\mathrm{N}^{\circ}$ & $\%$ \\
\hline Choque com objetos no ambiente de trabalho & 9 & 56,3 \\
Queda de peso sobre o corpo & 2 & 12,5 \\
Prensa & 2 & 12,5 \\
Ferramentas manuais & 1 & 06,3 \\
Máquinas e equipamentos & 1 & 06,3 \\
Dispositivo de transmissão de energia elétrica & 1 & 06,3 \\
\hline Total & 16 & 100,0 \\
\hline \hline
\end{tabular}

TABELA 4. Distribuição dos Acidentes de Trabalho na Empresa Metalúrgica Estudada, segundo Diagnóstic da Lesão

\begin{tabular}{lcc}
\hline \hline Diagnóstico & $\mathrm{N}^{\mathrm{o}}$ & $\%$ \\
\hline Ferimento corto-contuso sem fratura & 10 & 62,5 \\
Contusão, trauma com fratura $(*)$ & 3 & 18,8 \\
Contunsão, trauma sem fratura & 2 & 12,5 \\
Ferimento corto-contuso com fratura $(*)$ & 1 & 06,3 \\
\hline Total & 16 & 100,0 \\
\hline \hline
\end{tabular}

(*) Acidentes considerados graves 
TA BE LA 5. Distribuição dos Acidentes de Trabalho na Empresa Metalúrgica Estudada, segundo a Localização da Lesão

\begin{tabular}{lcc}
\hline \hline Localização da Lesão & $\mathrm{N}^{\mathrm{o}}$ & $\%$ \\
\hline Dedos & 7 & 43,8 \\
Antebraço & 3 & 18,8 \\
Mão & 2 & 12,5 \\
Faces & 1 & 06,3 \\
Tórax & 1 & 06,3 \\
Braço & 1 & 06,3 \\
Artelho & 1 & 06,3 \\
\hline Total & 16 & 100,0 \\
\hline \hline
\end{tabular}

TA BELA 6. Distribuição dos Acidentes de Trabalho na Empresa Metalúrgica Estudada, segundo a Função do Trabalhador

\begin{tabular}{lccl}
\hline \hline Localização da Lesão & $\mathrm{N}^{\mathrm{o}}$ & $\%$ & $\begin{array}{l}\text { Setor de Trabalho dos } \\
\text { Acidentados }\end{array}$ \\
\hline Prensista & 5 & 31,3 & Estamparia \\
Ajudante geral & 4 & 25,0 & Estamparia \\
Ferramentaria de manutenção & 2 & 12,5 & Ferramentaria \\
Meio-oficial ajustador & 1 & 06,3 & Ferramentaria \\
Líder de estamparia & 1 & 06,3 & Estamparia \\
Mandrilhador & 1 & 06,3 & Ferramentaria \\
Operador de empilhadeira & 1 & 06,3 & Estamparia \\
Serviços gerais & 1 & 06,3 & Adm. Pessoal \\
\hline Total & 16 & 100,0 & \\
\hline \hline
\end{tabular}

\section{O Enfoque dos Trabalhadores}

Dos 16 trabalhadores, apenas cinco compareceram à reunião marcada. A comparação entre os dados da causa do acidente, codificados pelo sistema de vigilância epidemiológica a partir da descrição da causa do acidente na CAT, e o relato dos acidentes pelos trabalhadores pode ser observada na Quadro 1. Ficam evidentes as limitações da compreensão das circunstâncias do acidente estabelecidas pela codificação. A descrição contida na CAT também pouco ajuda para a inferência da multicausalidade envolvida no acidente. Essa descrição passa pelo filtro do funcionário da empresa que preenche a CAT que, na maioria das vezes, não presenciou a ocorrência. A multicausalidade só se torna mais nítida quando o trabalhador relata as circunstâncias em que sofreu o acidente.
Apenas para ressaltar a diferença qualitativa das informações contidas na CAT e as fornecidas pelos trabalhadores, alguns pontos contidos na Quadro 1 serão detalhados a seguir. Observando-se as causas dos acidentes nas CATs dos trabalhadores 3 e 4 descritas no Quadro, no caso 3 a codificação identifica como causa "máquinas e equipamentos", quando, na verdade, o acidente ocorreu em uma serra sem proteção no ponto de operação. A descrição do acidente na CAT sugere que o trabalhador ativamente bateu o polegar contra uma superfície sem proteção. Na descrição feita pelo trabalhador, dois outros fatores entram em jogo: o ritmo de trabalho e a necessidade de improvisação para a adequação da ferramenta. No caso 4, observa-se um erro de codificação do sistema de vigilância, pois a causa deveria ter sido anotada como "máquinas e equipamentos", e 


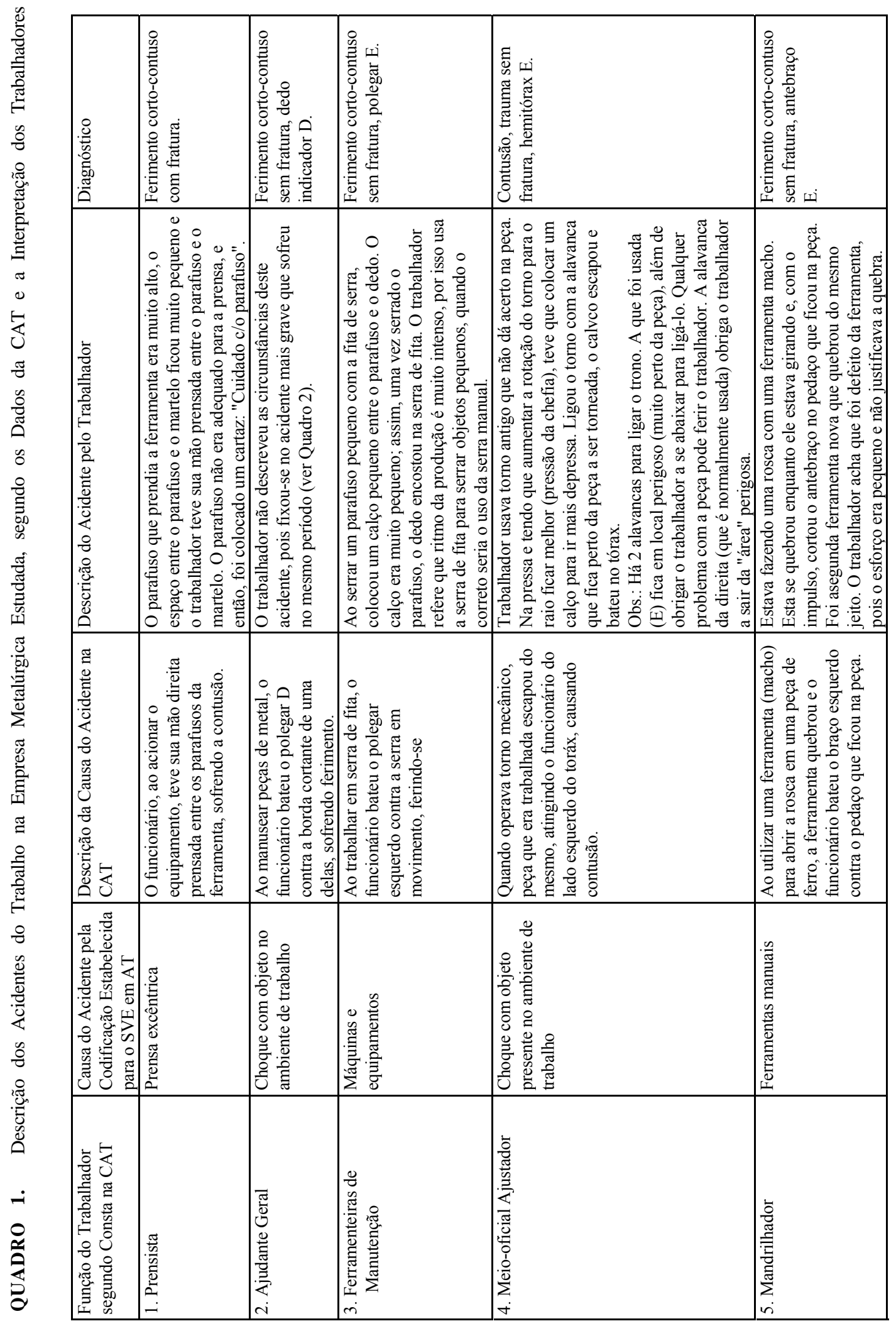


não "choque com objeto presente no ambiente de trabalho". A descrição da causa na CAT também é restritiva e somente o relato do trabalhador estabelece a lógica causal: "usava torno antigo, inadequado para a peça a ser trabalhada, necessitando improvisar para trabalhar no ritmo de produção exigido pela empresa". No caso 1 , também é difícil imaginar a situação ocorrida pela descrição da CAT. No entanto, conhecendo a versão do trabalhador, constata-se que havia um parafuso inadequado para a máquina, fato conhecido pela empresa, tendo inclusive gerado a colocação de um cartaz: "Cuidado com o parafuso".

Deste encontro com os trabalhadores, além do olhar mais profundo sobre a causalidade, um fato acabou por enriquecer a experiência aqui descrita. Um dos trabalhadores rastreado através do sistema por um acidente não grave que sofrera e presente à reunião chamou a atenção por apresentar amputação da mão esquerda. A amputação era decorrente de outro acidente ocorrido no final do mês de dezembro, portanto, dentro do periodo estudado.

Esta ocorrência tornou-se um dos eixos da discussão e acabou canalizando as preocupações em relação ao ambiente de trabalho na empresa. Alguns pontos a considerar: (a) falha de detecção deste fato pelo sistema de informação. Embora o acidente tenha ocorrido em uma empresa situada na região do SUDS-R-6, o atendimento médico foi prestado por serviço localizado fora do SUDS-R-6. Como a lógica do sistema é regida pelas contas hospitalares de instituições localizadas neste SUDS, explica-se o fato do acidente não ter sido devidamente detectado; (b) o relato do paciente comprovou as conhecidas deficiências da atenção médica prestada ao acidentado do trabalho; e (c) a questão do risco de gravidade potencial que envolve os acidentes leves. Este trabalhador teve um acidente considerado leve (caso 2 do Quadro 1) e pouco tempo depois sofreu outro, desta vez grave. As causas deste acidente referidas na CAT e a descrição pelo trabalhador podem ser observadas na Quadro 2.

\section{O Enfoque da Empresa}

Após o encontro com os trabalhadores, programou-se uma visita ao local, realizada sem comunicação prévia à empresa. Esta estratégia é importante, já que visitas programadas com antecedência e em comum acordo com os diretores podem se tornar um ato meramente burocrático. A expectativa da visita cria situações artificais que não refletem as condições diárias do ambiente de trabalho.

A empresa, através de um dos diretores e do supervisor de segurança, recebeu com estranheza os números apresentados. A discussão, embora percorrendo todos os acidentes do período, centrou-se na amputação da mão. As conclusões da Comissão Interna de Prevenção de Acidentes (CIPA) e as observações do supervisor de segurança em relação a este acidente estão no Quadro 2, onde fica clara a ênfase no argumento do "ato inseguro". $\mathrm{Na}$ visita à área de produção, chamou a atenção o fato de, em todas as prensas, os equipamentos de segurança serem inadequados. A prensa onde havia ocorrido a amputação estava, naquele momento, sendo operada por três trabalhadores. O sistema de cortina de célula fotoelétrica estava desligado e apenas dois duplos comandos estavam em uso; portanto, as mesmas condiçoes inadequadas descritas pelo trabalhador na reunião (ver Quadro 2).

As condições de operação dos equipamentos mostravam-se compatíveis com os dados apontados pelo sistema de informação, confirmando a indicação de alto risco daquele ambiente de trabalho.

\section{DISCUSSÃO E CONCLUSÕES}

A vigilância em saúde é um processo dinâmico que deve, permanentemente, fornecer elementos para uma intervenção organizada sobre aqueles fatores que se constituem em riscos à saúde, objetivando modificar os padrões de morbi-mortalidade na população. A experiência desta investigação apresenta os três componentes de um sistema de vigilância: levantamento das informações, análise de dados e ação (Fischman, 1986; Fossaert et al., 1974; Landrigan, 1989).

A participação dos trabalhadores acidentados permitiu ampliar o conhecimento sobre os múltiplos fatores causais envolvidos nos acidentes ocorridos na empresa e sobre os quais as 


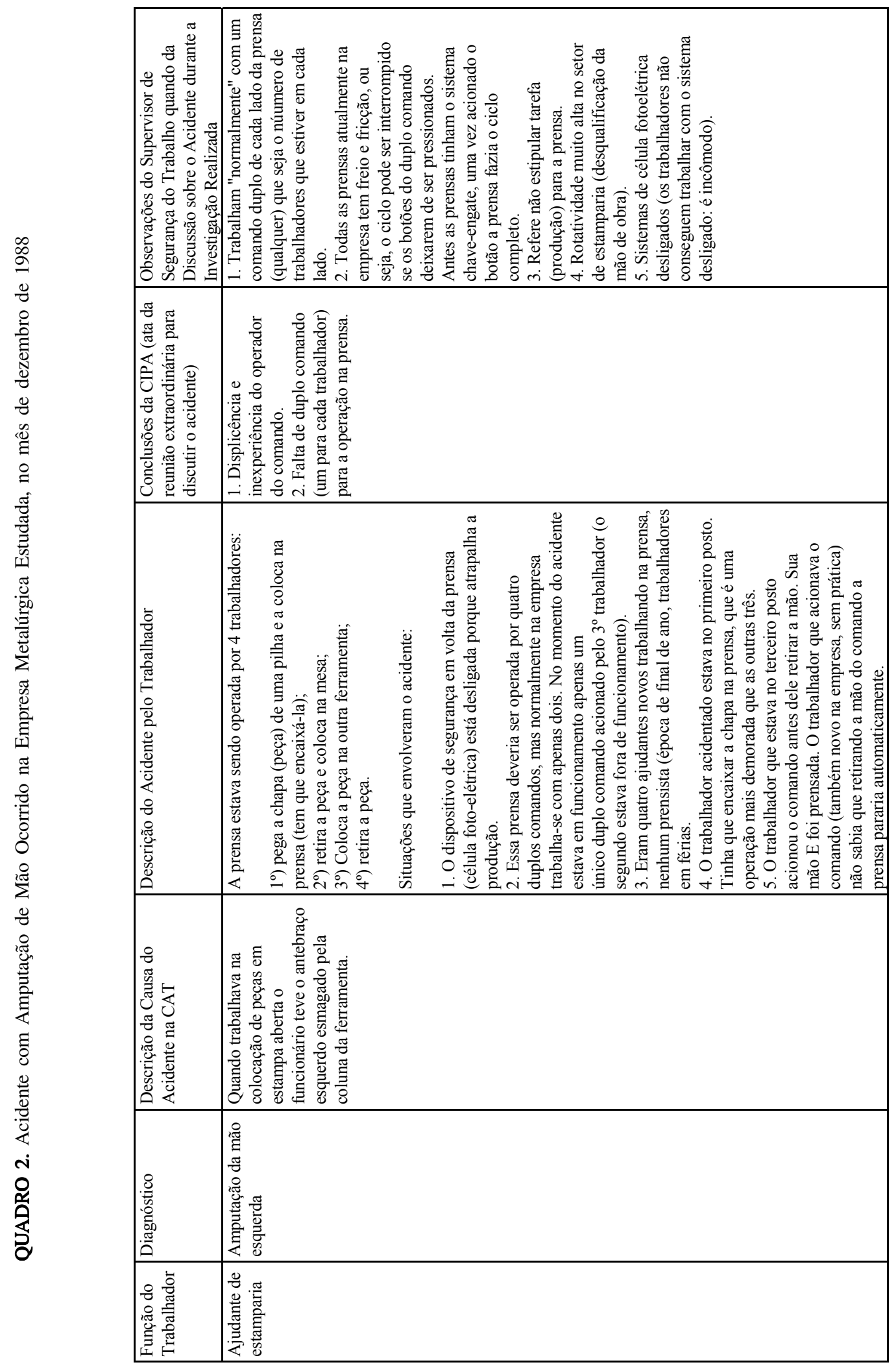


informações, no contexto da CAT, são geralmente insuficientes. $\mathrm{O}$ sistema de vigilância em acidentes do trabalho em operação no SUDS-R6 , embora limitado no aspecto qualitativo da causalidade e também na agilidade de detecção do acidente, indicou, quantitativamente e com adequação, a empresa metalúrgica que devia ser investigada. Não é possível calcular o coeficiente de freqüência,

$$
\text { C.F. }=\frac{n^{o} \text { de acidentes/lesões } X 1.000 .000}{n^{o} \text { de homens/hora exposto ao risco }}
$$

uma vez que os acidentes registrados não representam todos os ocorridos no período estudado na empresa.

Quando se busca avaliar o problema dos acidentes de trabalho, deve-se considerar a intrínseca conexão existente entre o processo de produção e o processo de saúde-doença nos trabalhadores. O processo de produção é composto pelo processo técnico de produção, caracterizado pelo maquinário, equipamento e matérias-primas,e pela organização social do trabalho, que envolve a determinação da jornada e do turno de trabalho e, também, o controle dos trabalhadores e das tarefas. Dentro deste contexto, outro aspecto que deve ser levado em consideração são as próprias condições de saúde dos trabalhadores, determinadas pela origem de classe social, relacionadas às suas condições de nutrição, habitação, lazer e realizações familiares e sociais (Laurell \& Noriega, 1989; Medrado Faria et al., 1983).

No conjunto dos acidentes do trabalho aqui analisados, nota-se a contribuição dos componentes do processo de produção em cada situação de ocorrência do acidente. É evidente que, nos acidentes com prensas e serras, devese pensar nos mecanismos de proteção destas máquinas que se estivessem funcionando não teriam gerado o acidente. Nos acidentes 3 e 4 do Quadro 2 está clara a multicausalidade, envolvendo tanto aspectos do processo técnico de produção como da organização social do trabalho.

É responsabilidade da empresa prover a segurança para a operação dos equipamentos de trabalho. A atitude empresarial é geralmente identificar o problema como "ato inseguro" do trabalhador. Este é um enfoque distorcido e de certa forma já sedimentado por uma determina- da cultura nas áreas da Medicina Ocupacional e da Engenharia de Segurança, sendo, inclusive, muitas vezes absorvido pelo trabalhador. $\mathrm{O}$ operário que teve a mão amputada, por exemplo, embora identificasse parte dos problemas estruturais que haviam favorecido o acidente, apontava para uma certa culpabilidade daquele terceiro trabalhador que operava na prensa o único comando duplo. A vivência concreta da perda às vezes não permite elaborações abstratas, relacionando fatores ligados ao processo de produção como fonte geradora do acidente. A empresa que, por força da lei, não pode demitílo sutilmente busca reduzir sua responsabilidade. A argumentação dos representantes da empresa aborda as circunstâncias do acidente no contexto da organização do trabalho, mas através de uma óptica própria. $\mathrm{O}$ fato do termo "displicência" preceder o termo "inexperiência" no relatório da CIPA (Quadro 2) deixa claro o ardil: é o operário que, com seu desinteresse pelo trabalho, desencadeou o ato inseguro que gerou o acidente. A "inexperiência" fica em segundo plano no relatório, já que seria responsabilidade da empresa capacitar seus funcionários para a operação de suas máquinas. Ainda no tocante à empresa, o supervisor de segurança do trabalho referiu que não estipula produção para as operações na prensa. Alguns fatos sugerem o contrário, deixando implícita a existência de um determinado ritmo de produção. O acidente ocorreu pela manhã, por volta das 10:00 horas. O período de final de ano e também a época de férias levaram os administradores da empresa a estabelecerem o uso de apenas um duplo comando para acionar a prensa, a manterem desligado o sistema de célula fotoelétrica e a alocarem trabalhadores inexperientes na atividade com prensas.

Outro aspecto que merece atenção é saber quais mudanças efetivamente ocorreram no ambiente de trabalho desta fábrica após a intervenção realizada pelo PST. A ação dos técnicos do programa foi pontual e, evidentemente, isso não representa garantia de mudanças no ambiente de trabalho. Somente os trabalhadores organizados, exercendo o seu direito de cidadania, é que podem assegurar as mudanças necessárias nos seus locais de trabalho. Os técnicos da área de saúde não podem garantir conquistas. Imagine, a título de exemplo, uma 
situação concreta. Na área de abrangência do SUDS-R-6 existem cerca de 2.400 empresas industriais. caso se estabelecesse como estratégia de trabalho visitar todos os ambientes fabris da região e, utilizando-se a capacidade operacional máxima, fossem visitadas duas empresas por dia, só se retornaria à primeira empresa visitada em um período de cinco anos. Parece clara a inviabilidade desta estratégia como prática transformadora.

Oddone, na Itália (1986) e, mais recentemente, Laurell, no México (1989), têm discutido propostas no sentido de um trabalho junto aos sindicatos de trabalhadores para a compreensão e percepção do processo de produção. Laurell, trabalhando com operários de uma siderúrgica, está em contato com uma parcela de trabalhadores organizados e com preocupações mais definidas nas questões de saúde. Nesta situação, mesmo sem contato com o ambiente laborativo, os técnicos conseguem reter uma nítida percepção dos riscos presentes naquele ambiente, riscos esses que Laurell conceitua como cargas de trabalho. Buscamos também, a nível de serviço, resgatar a experiência operária. No entanto, num sistema de vigilância em saúde, deve-se considerar ações permanentes, diárias, rotineiras. Esta rotina de serviços apresenta características e, muitas vezes, objetivos diversos do mundo acadêmico. Quando nos referimos a um sistema de vigilância a nível local, estamos, na verdade, falando de um sistema de informação para a ação, e, neste nível, nem sempre há a oportunidade de se trabalhar com as parcelas operárias mobilizadas para a questão da saúde. Esta situação está presente neste estudo. A categoria dos metalúrgicos tem pouca organização sindical na zona norte da cidade de São Paulo. Não se trata aqui de discutir os rumos e prioridades do movimento sindical em São Paulo ou em determinada região da cidade de São Paulo. Constata-se o fato. Há diferentes formas de organização dos trabalhadores, a nível sindical e a nível dos locais de trabalho, e uma não substitui a outra. Não há dúvida de que o trabalho articulado com uma categoria profissional em que haja respaldo sindical resulta em maiores ressonância e efetividade. Entretanto, quando esta situação ideal não existe, os técnicos devem manter contato com os trabalhadores e, deste contato, buscar formas de atuação efetivas para suas intervenções nos ambientes de trabalho.

Outro ponto que deve ser discutido é sobre as estratégia de ação a ser desenvolvida a partir dos dados levantados pelo sistema de informações. A conclusão é que as linhas de ação não são excludentes, ou seja, deve-se estar atento tanto àquelas empresas que apresentam grande número de acidentes quanto investigar os acidentes graves. A nível local, é necessário estruturar um banco de dados sobre as empresas da região. É somente com essas informações que podem ser definidos os riscos por empresa. Nem sempre as empresas com menor número de acidentes são as menos perigosas. Já foi apontada, em estudo da década de 70, a importância das pequenas empresas industriais na questão dos acidentes do trabalho em São paulo (Mendes, 1975). É necessário saber o número de empregados da empresa para estabelecer o risco proporcional.

Ficaram evidentes, também, as limitações do instrumento de comunicação de acidentes de trabalho. A CAT deve necessariamente ser repensada. Criada para fins de registro legal do trabalhador acidentado, ela deve sofrer modificações para que possa cumprir o duplo papel de continuar a ser a base legal do acidentado e também servir aos objetivos de um sistema de informação em saúde.

Deve ser considerado, ainda, nessas reflexões, o modelo assistencial aos acidentados do trabalho. O paciente que teve a mão amputada demorou cerca de três horas para receber atendimento médico. Logo após o acidente, o trabalhador foi levado a um hospital credenciado privado dentro da área do SUDS-R-6. Por falta de condições o atendimento, foi transportado para um hospital-escola, referência terciária da cidade de São Paulo, o qual, alegando não ter credenciamento para atender acidentes do trabalho, embora legalmente não exista esta necessidade, remeteu o paciente para um hospital credenciado localizado no SUDS-R-1, região contígua ao SUDS-R-6. Dois pontos ficam evidentes nesta situação: a incoerência dos hospitais públicos não atenderem acidentados do trabalho e a falta de um sistema mínimo de referência e contra-referência.

Finalmente, julgamos que a abrangência do sistema de vigilância em saúde em São Paulo e 
em outras regiões do país deve buscar incorporar os eventos patológicos não-transmissíveis. A monitoria destas ocorrências colocará o sistema em sintonia com as transições processadas pela população brasileira. No que diz respeito à saúde dos trabalhadores, as informações geradas pelo sistema darão suporte para o planejamento das atividades dos programas, as quais serão traduzidas em ações mais efetivas para mudanças no ambiente e no processo de trabalho, bem como no encaminhamento de soluções para as graves distorções do modelo assistencial.

O sistema de informação, a nível local, deve articular-se não só com outros níveis locais para a troca de informações, mas também com outras instâncias, de níveis regional e central. Somente assim estará caracterizado um sistema de vigilância em saúde. As informações consolidadas em níveis centrais devem servir de subsídios para a elaboração de uma legislação específica e para a política de planejamento do espaço geográfico, direcionando a organização urbana, levando-se em consideração áreas de industrialização, de moradia, de lazer e do fluxo de tráfego.

O sistema de vigilância que entendemos, particularmente neste aspecto dos acidentes e doenças do trabalho, só poderá se tornar realidade com a efetiva municipalização dos serviços e com a integração entre as diversas regiões de saúde, realizadas dentro do espirito da Reforma Sanitária. A efetividade do sistema e das ações transformadoras só estará garantida com a participação dos principais interessados — os trabalhadores.

\section{RESUMO}

WÜNSCH-FILHO, V.; SETTIMI, M. M.; FERREIRA, C. S. W.; CARMO, D. C.; SANTOS, U. P.; MARTARELLO, N. A. \& COSTA, D. F. Sistema de Informação para a Ação: Subsídios para a Atuação Prática dos Programas de Saúde dos Trabalhadores a Nível Local. Cad. Saúde Públ., Rio de Janeiro, 9 (2): 136-148, abr/jun, 1993.

Nas últimas décadas o Brasil transformou-se em uma sociedade industrializada. A partir da perspectiva epidemiológica e considerando as mudanças que estão ocorrendo a população brasileira, particularmente nos aspectos da transição demográfica, discute-se neste trabalho a necessidade de repensar a abrangência e prioridade do sistema de vigilância epidemiológica no país. O estudo avalia o sistema de informação para a ação de acidentes do trabalho a nível local, implantado no Programa de Saúde dos Trabalhadores do SUDS-R-6 (Mandaqui), tendo por base os dados de uma empresa metalúrgica da região que o sistema identificava como apresentando um processo de produção com alto risco de acidentes. A participação dos trabalhadores acidentados na discussão sobre os riscos ambientais e processo de trabalho, permitiu esclarecer a multicausalidade envolvida nos acidentes ocorridos nesta empresa. É destacada a importância da participação dos trabalhadores organizados - através de seus sindicatos, nas ações de controle dos acidentes. Embora, nem sempre essa participação organizada seja possível, o setor saúde deve buscar formas de atuação que resgatem a experiência concreta dos trabalhadores.

Palavras-Chave: Programa de Saúde Ocupacional; Vigilância Epidemiológica; Acidentes do Trabalho 


\section{REFERÊNCIAS BIBLIOGRÁFICAS}

ANÔNIMO, 1989. Editorial. Revista Brasileira de Saúde Ocupacional, 67: 1.

COSTA, D. F.; CARMO, J. C.; SETTIMI, M. M. \& SANTOS, U. P. (orgs.), 1989. Programa de Saúde dos Trabalhadores. A experiência da Zona Norte: U ma Alternativa em Saúde Pública. São Paulo: Hucitec.

DE CICCO, F. M. G. A. F., 1982. Estatísticas de A cidentes do Trabalho, Brasil 1980. São Paulo: Fundacentro.

CHAIA, M. W., 1988. Estado, família e desemprego. São Paulo em Perspectiva, 2: 16-19.

DEDECCA, C. S. \& FERREIRA, S. P., 1988. Crescimento econômico e população economicamente ativa. São Paulo em Perspectiva, 2: 4355.

FISCHMAN, A., 1986. Vigilância epidemiológica. In: Epidemiologia e Saúde (M. Z. Rouquayrol, org.), pp. 319-341, Rio de Janeiro: Medsi.

FOSSAERT, H.; LLOPIS, A. \& TIGRE, C. H., 1974. Sistemas de vigilância epidemiológica. Boletin de la Oficina Sanitaria Panamericana, 76: 512-528.

SEADE (Fundação Estadual de Análise de Dados), 1987. A nuário Estatístico do Brasil: 1983-1986. São Paulo: Fundação Seade.

KALACHE, A.; ERAS, R. P. \& RAMOS, L. R., 1987. O envelhecimento da população mundial: um desafio novo. Revista de Saúde Pública, 21: 200-210.

LANDRIGAN, P. J., 1989. Improving the surveillance of occupational disease (editorial). A merican Journal of Public Health, 79: 1601-1602.

LAURELL, A. C. \& NORIEGA, M., 1989. Processo de Produção e Saúde. Trabalho e Desgaste O perário. São Paulo: Hucitec.

MENDES, R., 1975. Importância das Pequenas Empresas Industriais no Problema de Acidentes de Trabalho em São Paulo. Tese de Mestrado, São Paulo: Faculdade de Saúde Pública, Universidade de São Paulo.

ODDONE, I.; MARRI, G.; GLORIA, S.; BRIANTE, G.; CHIATTELLA, M. \& RE, A., 1986. Ambiente de Trabalho: A Luta dos Trabalhadores pela Saúde. São Paulo: Hucitec.
OLIVEIRA, F., 1988. O flanco aberto. São Paulo em Perspectiva, 2: 10-12.

MEDRADO-FARIA, M. A.; GUIMARÃES, O. M. A.; CASTILHO, E. A.; BEZERRA, W.; ROCHA, L. E. \& ALVARENGA, A. I., 1983. Saúde e trabalho: acidentes de trabalho em Cubatão. Revista Brasileira de Saúde Ocupacional, 42: 7-22.

POSSAS, C. A., 1981. Saúde e Trabal ho. A Crise da Previdência Social. Rio de Janeiro: Graal. , 1987. Contribuição para a definição de um sistema nacional de informações e acidentes do trabalho. Previdência em Dados, 2: 13-24. 1989. Epidemiologia e Sociedade. Heterogeneidade Estrutural e Saúde no Brasil. São Paulo: Hucitec.

RAMOS, L. R.; VERAS, R. P. \& KALACHE, A., 1987. Envelhecimento populacional: uma realidade brasileira. Revista de Saúde Pública, 21: 211-224.

ROGMANS, W., 1989. National programmes on accident and injury prevention. The role of the health sector. First World Conference on Accident and Injury Prevention. Stockholm, September 21-22. (Comunicação Pessoal)

SAAD, P. M. \& CAMARGO, A. B. M., 1989. O envelhecimento populacional e suas consequiências. São Paulo em Perspectiva, 3: 40-45.

SANTOS, U. P.; WÜNSCH-FILHO, V.; CARMO, J. C.; SETTIMI, M. M.; URQUISA, S. D. \& HENRIQUES, C. M. P., 1990. Sistema de vigilância epidemiológica para acidentes do trabalho: experiência da zona norte do município de São Paulo. Revista de Saúde Pública, 24: 286-293.

SANTOS, U. P.; WÜNSCH-FILHO, V.; URQUIZA, S. D. \& HENRIQUES, C. M. P., 1989. Routine information system of work accidents in a delimited area of São Paulo city, Brazil. Abstract Guide. First World Conference on Accident and Injury Prevention. Stockholm, September 17-20. (Mimeo.)

TROYANO, A. A., 1988. Como medir o desemprego numa economia subdesenvolvida. São Paulo em Perspectiva, 2: 13-15.

VERAS, R. P.; RAMOS, L. R. \& KALACHE, A., 1987. População idosa no Brasil: transformações e consequiências na sociedade. Revista de Saúde Pública, 21: 225-233. 